\title{
Intracellular Trafficking of Factor VIII to von Willebrand Factor Storage Granules
}

\author{
Jonathan B. Rosenberg, ${ }^{\star}$ Paul A. Foster, ${ }^{\star \ddagger}$ Randal J. Kaufman, ${ }^{\S}$ Elizabeth A. Vokac, ${ }^{*}$ Micheline Moussalli, ${ }^{\S}$ Philip A. Kroner, ${ }^{\star}$ \\ and Robert R. Montgomery ${ }^{\star \ddagger}$ \\ *Blood Research Institute, The Blood Center of Southeastern Wisconsin, Milwaukee, Wisconsin 53201-2178; $\stackrel{*}{*}$ epartment of Pediatrics, \\ The Medical College of Wisconsin, Milwaukee, Wisconsin 53226; and ${ }^{\S}$ Department of Biological Chemistry, Howard Hughes Medical \\ Institute, University of Michigan Medical School, Ann Arbor, Michigan 48109
}

\begin{abstract}
In plasma, von Willebrand factor (vWf) associates with Factor VIII (FVIII); however, the site at which these proteins first interact has not been defined. Administration of 1-desamino-8-D-arginine vasopressin (DDAVP) causes a rapid, concomitant elevation in plasma levels of both $\mathrm{vWf}$ and FVIII, suggesting the existence of a DDAVP-releasable storage pool for both proteins. To determine whether vWf and FVIII can associate intracellularly and colocalize to storage vesicles, we transfected AtT-20 cells with vWf and FVIII expression plasmids. FVIII alone was not detectable within storage granules; however, transfection of vWf cDNA into the same cell caused FVIII to alter its intracellular trafficking and to undergo granular storage, colocalizing to the vWf-containing granules. In contrast, colocalization of FVIII was not observed when these cells were transfected with plasmids encoding defective FVIII-binding vWf mutants. Transfection of bovine endothelial cells with FVIII further demonstrated vesicular storage of FVIII with vWf in Weibel-Palade bodies. Since gene therapy of hemophilia A may ultimately target endothelium or hematopoietic stem cells, the interaction between vWf and FVIII within a secretory cell is important. Thus, vWf can alter the intracellular trafficking of FVIII from a constitutive to a regulated secretory pathway, thereby producing an intracellular storage pool of both proteins. (J. Clin. Invest. 1998. 101:613-624.) Key words: hemophilia A - molecular chaperones - vascular endothelium $\bullet$ protein sorting $\bullet$ carrier proteins
\end{abstract}

\section{Introduction}

vWf and Factor VIII (FVIII) ${ }^{1}$ are critical hemostatic proteins. Reduced levels of either protein result in the common bleeding disorders von Willebrand disease (vWD) and hemophilia A, respectively. Treatment of mild vWD or mild hemophilia A involves the use of 1-desamino-8-D-arginine vasopressin (DDAVP) to arrest the bleeding episode by stimulating the endogenous release of both $v$ Wf and FVIII $(1,2)$. Immediately

Address correspondence to Robert R. Montgomery, Blood Research Institute, The Blood Center of Southeastern Wisconsin, P.O. Box 2178, Milwaukee, WI 53201-2178. Phone: 414-937-6318; FAX: 414937-6284; E-mail: bob@smtpgate.bcsew.edu

Received for publication 21 July 1997 and accepted in revised form 8 December 1997.

J. Clin. Invest.

(C) The American Society for Clinical Investigation, Inc. 0021-9738/98/02/0613/12 \$2.00

Volume 101, Number 3, February 1998, 613-624

http://www.jci.org after the administration of DDAVP, there is a rapid and concomitant increase in the plasma levels of both FVIII and vWf in normal individuals as well as in patients with mild vWD or mild hemophilia A (3-6). The absence of similar elevations in plasma FVIII levels in severe vWD (type 3) patients after treatment with DDAVP suggests that such patients fail to establish a storage pool of FVIII (7). Although DDAVP-stimulated release of FVIII in normal individuals suggests an intracellular storage pool of FVIII, subcellular deposits of FVIII have not been defined clearly in vivo. Only one report has shown FVIII in irregular staining patterns in vascular tissue (8). In contrast, vWf is stored in releasable granules in platelets and endothelial cells $(9,10)$, although the source of the DDAVP-stimulated $\mathrm{vWf}$ release has been ascribed primarily to the endothelium and not the platelet $(11,12)$. The goal of our study was to determine whether a storage pool of both vWf and FVIII will form in a cell capable of intracellular storage and whether vWf can alter the secretory trafficking of FVIII into this storage pool.

While vWf serves two crucial functions in hemostasis (13), this manuscript will further define its function as an intracellular chaperone, in addition to its known role as the extracellular carrier of FVIII. Intracellularly, vWf undergoes a sequential series of posttranslational modifications in the rough endoplasmic reticulum and Golgi network, including dimerization, glycosylation, sulfation, multimerization, and propolypeptide cleavage (14). Vesicular transport of secretory proteins, such as vWf, occurs through two distinct secretory pathways in the trans-Golgi network (TGN), resulting in constitutive secretion and regulated storage (15-17). vWf becomes highly concentrated and is segregated into dense intracellular granules termed Weibel-Palade bodies (WPB) in endothelial cells and $\alpha$-granules in platelets (14). These granules of vWf constitute the releasable storage pool of high molecular weight multimeric vWf (18). While multiple variants of vWD have been identified at both the functional and molecular level, we used two type $2 \mathrm{~N}$ vWD mutant proteins with reduced affinity of vWf for FVIII. Mutations causing type $2 \mathrm{~N}$ vWD have been mapped to the $\mathrm{NH}_{2}$ terminus of mature vWf, and led to a secondary deficiency in plasma levels of FVIII $(19,20)$. In this study, these mutant vWf proteins were expressed in cell lines to characterize the intracellular relationships between these mutant vWf molecules and FVIII.

FVIII is a large heterodimeric plasma glycoprotein that is

1. Abbreviations used in this paper: BAEC, bovine aortic endothelial cells; 8-Br-cAMP, 8-bromoadenosine 3':5'-cyclic monophosphate; $\mathrm{CHO}$, Chinese hamster ovary; CLSM, confocal laser scanning microscopy; DDAVP, 1-desamino-8-D-arginine vasopressin; FVIII, Factor VIII; HUVEC, human umbilical vein endothelial cells; TGN, transGolgi network; TXR, Texas red; vWD, von Willebrand disease; WPB, Weibel-Palade bodies; WT, wild-type. 
an essential component of the intrinsic blood coagulation pathway, serving as the cofactor for the Factor IXa-dependent, "factor X-ase" activation complex (21). FVIII has been detected by mRNA hybridization and immunoperoxidase staining in a wide variety of tissues including liver, spleen, lymph node, kidney, and placental extracts $(8,22,23)$. Over the past several decades, several experimental therapies involving the transplantation of reticuloendothelial tissue have successfully "cured" hemophilia A in humans (liver and spleen tissue) and dogs (lymph node, liver, and spleen) (24-28). Nevertheless, the cellular site of FVIII production has not been identified conclusively, undoubtedly due to FVIII's low plasma and cellular concentration (22). The extracellular interaction between $\mathrm{vWf}$ and FVIII has been the subject of intensive study; however, it is not known where these two proteins first interact to form the noncovalent complexes that exist in plasma and that make up the necessary pool for DDAVP-induced release. Since endothelial cells or megakaryocytes containing $\mathrm{vWf}$ may be a target for gene therapy of hemophilia A, understanding the biology of FVIII in the vWf-secreting cell is of great importance.

\section{Methods}

Antibodies. mAbs AvW-1, AvW-5, AvW-17, MBC 103.3, and MBC 213.8, and polyclonal anti-vWf and anti-FVIII antibodies were produced by the Hybridoma Core Laboratories of the Blood Research Institute. AvW-1 is a "neutral" noninhibitory antibody that recognizes the $\mathrm{COOH}$ terminus of mature vWf (20). AvW-5 and AvW-17 both recognize multimeric vWf on Western blots. MBC 103.3 detects human FVIII light chains, but is not inhibited by the binding of vWf to FVIII. MBC 213.8 is an anti-canine vWf $\mathrm{mAb}$ which also detects human and bovine vWf. F-8 is an immunoprecipitating anti-FVIII mAb which recognizes the $\mathrm{A} 2$ domain of the FVIII heavy chain, and was kindly provided by D. Pittman (Genetics Institute, Andover, MD) (29). The anti-ACTH mAb (O2A3) was obtained from DAKO Corp. (Carpinteria, CA).

Plasmids. The major expression constructs used in these experiments were: pvW198.1 (vWf) (20) and pMT2-BDVIII (FVIII) (30) plasmids. The FVIII construct used in this study has the entire FVIII B domain excised, removing amino acids 741-1639 (30). A full-length FVIII construct, pMT2-VIII (31), was used for the initial studies only. Mutant vWf plasmids used in this study were constructed previously in pvW198.1, recreating known type 2N vWD patient DNA defects: one with an R91Q substitution (20) and one with a pro-vWf cleavage defect, which leads to the hereditary persistence of pro-vWf (HPPvWf) (32). The HPPvWf construct used in these experiments included a dinucleotide mutation ( $\Delta 2269-2270)$, which exposes a cryptic splice site in the patient's mRNA (32). This results in a loss of cleavage of vW AgII from mature vWf and the secretion of only pro$\mathrm{vWf}$. The mature $\mathrm{NH}_{2}$-terminal amino acids of $\mathrm{vWf}$ remain intact, but the $\mathrm{NH}_{2}$ terminus of this defective vWf retains the uncleaved propolypeptide, vW AgII (32). Plasmids used as stable selection plasmids in the transfection experiments included pcDNA3 (Invitrogen, San Diego, CA) or pCI-Neo (Promega, Madison, WI), which both contain the neomycin resistance gene enabling selection of transfected cells with Geneticin (G418) (Sigma Chemical Co., St. Louis, MO).

Cell cultures. Three different established cell lines were used in the course of this study: mouse pituitary tumor cells (AtT-20/D16v-F2 cells, CRL 1795) (American Type Culture Collection, Rockville, MD); monkey kidney cells (COS-7, CRL 1651) (American Type Culture Collection); and human embryonic kidney cells (HEK-293T) which were kindly provided by D. Ginsburg (University of Michigan, Ann Arbor, MI). Human umbilical vein endothelial cells (HUVEC) and bovine aortic endothelial cells (BAEC) were isolated from primary tissues and established in cell culture. Cells were used at third to fifth passages for the transfection studies. AtT-20 cells are a model storage and secretory cell line which are negative for vWf and FVIII synthesis, but positive for the hormone ACTH production and storage (33). One additional cell line used was a Chinese hamster ovary (CHO) cell line (10A1) that expresses wild-type FVIII (31). All cell lines were cultured at $37^{\circ} \mathrm{C}$ in $5 \% \mathrm{CO}_{2}$ in complete medium: DME with high glucose (Life Technologies, Gaithersburg, MD), 10\% FBS, and $2 \mathrm{mM}$ L-glutamine. HUVEC and BAEC cultures were plated on gelatin (Sigma Chemical Co.) and cultured in the same medium with the addition of sodium heparin $(6.45 \mathrm{U} / \mathrm{ml})$ (Sigma Chemical Co.) and endothelial cell growth supplement $(30 \mu \mathrm{g} / \mathrm{ml})$ (Collaborative Biomedical Products, Bedford, MA).

Mammalian cell transfections. To establish vWf and FVIII expressing cell lines, AtT-20 cells were individually transfected with pvW198.1 (WTvWf) and pMT2-BDVIII (BDD-FVIII) plasmids. Transfection conditions were optimized. $24 \mathrm{~h}$ before transfections, cells were plated at $7.3 \times 10^{4}$ cells $/ \mathrm{cm}^{2}$. A transfection mixture of 2 $\mu \mathrm{g} / \mathrm{ml}$ DNA plus $30 \mu \mathrm{g} / \mathrm{ml}$ LipofectAMINE (Life Technologies) was applied to the cells for $5 \mathrm{~h}$ at $37^{\circ} \mathrm{C}$ in OptiMEM I (Life Technologies). The DNA/lipid complexes were then replaced with complete medium for $72 \mathrm{~h}$, allowing for transient expression of the plasmids. Conditioned media were harvested from the cells, centrifuged to remove cellular debris, and then either assayed fresh or frozen at $-80^{\circ} \mathrm{C}$ for later analysis. Finally, the cells were lysed or fixed for immunofluorescence staining. In some experiments, FVIII and vWf expression were augmented with the addition of $3 \mathrm{mM}$ sodium butyrate (Sigma Chemical Co.) to the cell media $24 \mathrm{~h}$ before harvesting samples (34). Minor variations in the transfection procedure were used for the COS-7, HEK-293T, and BAEC transfections: $2.1 \times 10^{4} \mathrm{cells} / \mathrm{cm}^{2}$ plated and $10 \mu \mathrm{g} / \mathrm{ml}$ LipofectAMINE per reaction. Additionally, transient transfections of COS-7 cells were performed with the various plasmids independently to create positive controls for ELISA and immunofluorescence staining.

AtT-20 stable transfections were established using the above optimized transfection conditions. Stable transfections included either wild-type (WT) vWf (pvW198.1), mutant HPPvWf, or BDD-FVIII constructs. All were cotransfected with a neomycin-resistance plasmid (pcDNA3), in order to introduce a selectable marker. The cells were detached with trypsin $48 \mathrm{~h}$ after transfection and diluted 1:10 in complete medium containing $0.3 \mathrm{mg} / \mathrm{ml} \mathrm{G} 418$ (Sigma Chemical Co.), and replated in 100-mm dishes. After 2 wk of selection, isolated colonies were picked with polished glass pipettes (35) and replated in 24well plates. After several weeks of selection, positive colonies were selected by analysis of the secreted vWf and FVIII by vWf capture ELISA and fluid-phase functional FVIII assay, respectively (described below). The highest producing cells in colonies identified by these assays were expanded and purified through two rounds of single cell limiting dilutions. The cells were retested for vWf and/or FVIII secretion before each expansion step. The purified stable vWf/ AtT-20 and FVIII/AtT-20 cell lines were used for the secondary transfections described below.

Functional analysis of expressed FVIII. Activated FVIII activity (FVIII:C) levels in the conditioned media were quantitated by a fluidphase assay, Coatest VIII:C/4 kit (DiaPharm, Franklin, OH). The procedure was a modification of the manufacturer's protocol to allow the test to be performed in 96-well microtiter plates. Polybrene (1 $\mathrm{mg} / \mathrm{ml}$ ) (Sigma Chemical Co.) was added to conditioned media from transfected endothelial cells $(64.5 \mu \mathrm{l} / \mathrm{ml}$ medium) before the assay to inactivate heparin, as recommended by the manufacturer's protocols. Briefly, $25 \mu \mathrm{l}$ of sample was added in triplicate to uncoated wells. Assay components, including phospholipid, Factor IXa, Factor X, and calcium chloride were added, and the plates were incubated for 10 $\min$ at $37^{\circ} \mathrm{C}$. The chromogenic Factor Xa substrate S-2222 was added, and the plate was transferred immediately to a ThermoMax microplate reader (Molecular Devices, Menlo Park, CA) preset at $37^{\circ} \mathrm{C}$. The plate was read kinetically at $405 \mathrm{~nm}$ for $10 \mathrm{~min}$ at $37^{\circ} \mathrm{C}$. The Factor Xa-dependent conversion of S-2222 is a function of the amount of FVIII:C in each well. A standard curve was constructed by plotting 
known amounts of recombinant human FVIII (r-hFVIII) (Baxter, Glendale, CA) against $V_{\max }$ at $405 \mathrm{~nm}$. The $V_{\max }$ of each reaction was converted to units of FVIII:C activity using the kinetic software program, SOFTmax, v. 2.34 (Molecular Devices). The sensitivity of this assay is $\sim 1.0 \mathrm{mU} / \mathrm{ml}$ of FVIII:C

Analysis of expressed $v W f$. vWf in conditioned media from the transfected AtT-20 and BAEC cells was analyzed by means of solidphase capture ELISAs (32) and functional fluid-phase assays $(32,36)$. The concentration of secreted or released vWf in the samples was determined by an antigen-capture vWf ELISA using immobilized AvW-1 (or MBC 213.8 for BAEC samples) as described previously (32). vWf antigen levels were expressed as nanograms per milliliter, measured against serially diluted normal pool human plasma plotted as a standard curve (assuming $10 \mu \mathrm{g} / \mathrm{ml}$ of vWf in NP). vWf was also assayed for its ability to bind platelets (36) and to bind FVIII. The FVIII-binding assays were done essentially as first described by Nishino et al. (37) and modified by Kroner et al. (20, 32). Briefly, microtiter plates were coated with AvW-1 (a noninhibitory antibody). Samples diluted to a vWf concentration of $100 \mathrm{ng} / \mathrm{ml}$, controls, and standards were added in $50-\mu 1$ aliquots in triplicate wells. Concentrations of the diluted samples were rechecked on separate plates using the vWf ELISA. In some assays, controls included endogenously secreted vWf collected from nontransfected HUVEC and BAEC cultures grown without cytokine or secretagogue stimulation. After a 2-h room temperature incubation, the captured $\mathrm{vWf}$ was incubated with wash buffer $\left(0.4 \mathrm{M} \mathrm{CaCl}_{2} / 50 \mathrm{mM}\right.$ Tris/ $\left.150 \mathrm{mM} \mathrm{NaCl}_{2}, \mathrm{pH} 7.4\right)$ for 30 min at $37^{\circ} \mathrm{C}$ to remove coexpressed FVIII. Diluted r-hFVIII ranging from 0 to $4 \mathrm{U} / \mathrm{ml}$ was then added to the wells $(50 \mu \mathrm{l})$, followed by a $1-\mathrm{h}$ incubation at $37^{\circ} \mathrm{C}$. The activity of the bound FVIII was then assayed using the chromogenic Coatest VIII:C/4 kit. In this binding assay the enzymatic reactions were performed at room temperature and were terminated with $50 \%$ acetic acid $(25 \mu \mathrm{l} /$ well). The FVIII activity was measured by an endpoint reading at $405 \mathrm{~nm}$. The amount of FVIII bound was calculated based upon a standard curve generated by the addition of serially diluted r-hFVIII to microtiter wells before the chromogenic FVIII assay.

Pulse-chase analysis of expressed proteins. To determine whether the stably transfected AtT-20 cells were synthesizing and processing FVIII and vWf correctly, cells were metabolically labeled and pulsechase experiments were performed, as described previously (38). The cells were starved in cysteine (Cys)/methionine (Met)-free media for $10 \mathrm{~min}$, and then labeled for $30 \mathrm{~min}$ by addition of $\left[{ }^{35} \mathrm{~S}\right] \mathrm{Met}$ and $\left[{ }^{35} \mathrm{~S}\right]$ Cys mix (Redivue Pro-Mix L- $\left[{ }^{35} \mathrm{~S}\right]$ ) (Amersham, Arlington Heights, IL) to the media. An excess of unlabeled Cys/Met plus aprotinin $(200 \mu \mathrm{g} / \mathrm{ml})$ was added for another $5 \mathrm{~h}$, and the cells were lysed with an NP-40-containing buffer (38). A protease inhibitor cocktail consisting of soybean trypsin inhibitor $(1 \mathrm{mg} / \mathrm{ml})$, and PMSF $(1 \mathrm{mM})$ was added to all medium and lysate samples immediately after harvest to prevent proteolytic degradation (31). FVIII and vWf in the conditioned media and lysates were immunoprecipitated with protein A-Sepharose CL-4B (Pharmacia Biotech Inc., Piscataway, NJ) beads coupled to mAb F-8 (29) and AvW-1 (20), respectively. The immunoprecipitates of both proteins were washed in a series of Triton X-100/ PBS buffers and eluted with $2 \%$ SDS as described previously (38). After elution from the beads, a portion of the FVIII samples was further treated with thrombin $\left(5 \mathrm{U} / \mathrm{ml}\right.$ at $37^{\circ} \mathrm{C}$ for $\left.30 \mathrm{~min}\right)$ before gel analysis (29). The immunopurified samples of FVIII and vWf were reduced with $\beta$-mercaptoethanol and electrophoresed on $8 \%$ SDSPAGE gels at $35 \mathrm{~V}$ for $16 \mathrm{~h}$. The gels were dried and proteins were visualized by autoradiography after enhancement by $\mathrm{En}^{3} \mathrm{Hance}(\mathrm{Du}-$ Pont, Boston, MA) for $30 \mathrm{~min}$.

Multimer analysis. To demonstrate that the secreted vWf was processed normally, examination of the multimeric pattern of the AtT-20-synthesized vWf was performed. Conditioned media samples from transfected AtT-20, HEK-293T, and BAEC cells were analyzed, including untreated and sodium butyrate-treated samples. The collected conditioned media samples were precleared using Sepharose $\mathrm{CL}-4 \mathrm{~B}$, and then immunoprecipitated using mAb AvW-1 coupled to Sepharose CL-4B. For these immunoprecipitations, beads were washed twice in a series of three buffers each containing modified Hepes-Tyrode buffer ( $20 \mathrm{mM}$ Hepes, $140 \mathrm{mM} \mathrm{NaCl}, 3 \mathrm{mM} \mathrm{KCl}, 12 \mathrm{mM}$ $\mathrm{NaHCO}_{3}, 1 \mathrm{mM} \mathrm{NaH} \mathrm{PO}_{4}, 0.002 \%$ Triton $\mathrm{X}-100, \mathrm{pH}$ 8.0) plus $1 \%$ BSA, $0.5 \mathrm{M} \mathrm{NaCl}$, or $0.04 \%$ SDS (32). Antigens were eluted with multimer gel sample buffer $(8 \mathrm{M}$ Urea/6\% SDS/13 mM Tris/1 mM EDTA/0.05\% bromophenol blue, $\mathrm{pH} 8.8$ ). Samples were electrophoresed through a horizontal $1.5 \%$ or $3.0 \%$ HGT(P) agarose (FMC Bioproducts, Rockland, ME) gel containing $1 \%$ SDS for $16 \mathrm{~h}$ at $40 \mathrm{~V}$. The proteins were transblotted to Immobilon-P (Millipore, Medford, MA) for $30 \mathrm{~min}$ at $35 \mathrm{~V}$ followed by $4 \mathrm{~h}$ at $50 \mathrm{~V}$. Membranes were blocked with $5 \%$ nonfat dry milk, incubated overnight with monoclonal antibodies against vWf (AvW-5 and AvW-17), and then incubated for $2 \mathrm{~h}$ with horseradish peroxidase-conjugated goat antimouse IgG (Pierce, Rockford, IL). Finally, membranes were treated with ECL chemiluminescent substrate (Amersham) and bands detected by exposure to x-ray film (BioMax film; Eastman Kodak, Rochester, NY).

Immunofluorescence microscopy. Visual detection of the intracellular locations of vWf and FVIII in transfected cells was accomplished with immunofluorescent antibody labeling and confocal laser scanning microscopy (CLSM) analysis. Negative controls (nontransfected cells and mock-transfected cells) were processed in parallel with each immunofluorescence labeling assay under the same conditions. Transfected cells were grown in 35-mm plates on poly-D-lysinetreated glass coverslips (Becton Dickinson, Bedford, MA) in DME/ G418 media. After $3 \mathrm{~d}$ of growth, the cells were fixed using 3.7\% buffered formalin, permeabilized in $1 \%$ Triton X-100 solution $(20$ $\mathrm{mM}$ Hepes $/ 300 \mathrm{mM}$ sucrose $/ 50 \mathrm{mM} \mathrm{NaCl} / 3 \mathrm{mM} \mathrm{MgCl} 2 \cdot 6 \mathrm{H}_{2} \mathrm{O}, \mathrm{pH}$ $7.0]$, and blocked in $2 \%$ normal donkey serum/PBS. Dual immunofluorescent labeling of the cells was accomplished using a sequential antibody staining method, in which the individual antibodies were incubated with the fixed cells in four sequential steps (each for $30 \mathrm{~min}$ at $\left.37^{\circ} \mathrm{C}\right)(35,39)$. Affinity-purified anti-vWf polyclonal antibodies and anti-FVIII monoclonal antibody (MBC 103.3) were used as primary antibodies and diluted at 2.5 and $5.0 \mu \mathrm{g} / \mathrm{ml}$ in $1 \% \mathrm{BSA} / \mathrm{HBSS}$, respectively. FITC- and Texas red (TXR)-conjugated donkey IgGs $(\mathrm{H}+\mathrm{L})$ $\left[\mathrm{F}\left(\mathrm{ab}^{\prime}\right)_{2}\right.$ fragments] (Jackson ImmunoLabs, West Grove, PA) were the secondary antibodies used for detection of the primary antibodies, and were diluted $1: 200$ or $1: 1,000$ in a $1 \%$ BSA/HBSS, respectively. In the figures displayed in this report, the presence of FVIII was detected by an anti-mouse FITC-conjugated IgG, while the presence of vWf was detected by an anti-rabbit TXR-conjugated IgG. Immunofluorescence detection was performed using an MRC 600 confocal laser imaging system equipped with a krypton-argon laser (Bio-Rad, Hercules, CA) and an epifluorescent microscope (Nikon, Melville, NY). Individual excitation filters were used for FITC and TXR fluorescence, with the emissions captured using dual filter blocks (K1 and K2) and background reduced by Kalman collection filtering. Cells were imaged by a series of $Z$ sections taken for each field, and the entire $Z$ series (12-25 images) combined into a stacked projection. The projections for each individual filter (FITC and TXR) were then merged using the Confocal Assistant software program (Bio-Rad). Computer-assigned colors were based on the intensities of bitmap overlaps, with colocalization of the two fluorochrome-conjugated antibodies represented by yellow pixels.

Secondary transient transfections of stable cell lines. Once individual stable cell lines were isolated and characterized, they were used in a series of secondary transfections in which various vWf constructs (WT and $2 \mathrm{~N}$ vWf mutants) were transfected into FVIII/AtT-20 stable cells. Two dysfunctional vWf clones (see the Plasmids section) which possessed defective FVIII-binding capabilities (type 2N vWD) were tested in these studies. Mutations were selected based upon known severe FVIII-binding defects. The plasmids were secondarily transfected into FVIII/AtT-20 cells, following the transfection procedures described above. Controls for these transfections were pCI-Neo transfected FVIII/AtT-20 cells (negative plasmid control) and WTvWf transfected FVIII/AtT-20 cells (positive control for 
FVIII binding and storage). The reverse experiments were also performed: BDD-FVIII was transfected into WTvWf/AtT-20 and HPPvWf/AtT-20 cells. After transient transfections, the mutant vWf/ FVIII transfectants were stained and viewed as described above. The conditioned media were analyzed by vWf ELISA and Coatest FVIII: $\mathrm{C} / 4$ kit, monitoring for changes in the secretion of vWf and FVIII. The transient transfections of each stable cell line have been repeated a minimum of six times. The efficiency of the transient transfections into FVIII/AtT-20 cells varied between 10 and 30\%, as determined by the number of cells displaying positive for vWf granular staining.

Stimulated release of storage granules. Stably transfected AtT-20 cells $\left(10^{6}\right.$ cells in $60-\mathrm{mm}$ plates grown to near confluency) were treated with $5 \mathrm{mM}$ 8-bromoadenosine $3^{\prime}: 5^{\prime}$-cyclic monophosphate (8-Br-cAMP) (Sigma Chemical Co.) for $1 \mathrm{~h}$ at $37^{\circ} \mathrm{C}$ (35). The FVIII-transfected BAEC cells $\left(4.5 \times 10^{5}\right.$ cells in 60 -mm plates grown to near confluency) were stimulated with either $10^{-6}$ M PMA (Sigma Chemical Co.) or $10^{-5} \mathrm{M}$ histamine (Sigma Chemical Co.) for $30 \mathrm{~min}$ at $37^{\circ} \mathrm{C} \mathrm{(40)}$. After the treatments, the transfected AtT-20 and BAEC cells were washed twice with HBSS and formalin-fixed as described above. Immunofluorescence microscopic analysis was then performed on these cells using the same detection antibodies and sequential staining as previously described. Each slide was evaluated for the appearance or disappearance of intracellular storage granules of vWf and FVIII.

\section{Results}

AtT-20 cells process FVIII and $v W f$ correctly into functional proteins. To investigate the nascent FVIII and vWf processing and trafficking in the secretory pathway of storage/secretory cells, we transiently transfected FVIII and vWf expression plasmids into AtT-20 cells. Since AtT-20 cells have not been used previously as a transfected host for FVIII, we have demonstrated by means of functional FVIII activity assays that the biosynthesis of FVIII occurred normally. The secreted AtT20-expressed FVIII has activity similar to that of transfected COS-7-expressed FVIII, although the transfection efficiency of the AtT-20 cells is markedly reduced in comparison. Initially, we performed the transfection experiments using a fulllength (fl) FVIII plasmid construct, but fl-FVIII transfected AtT-20 cells secreted FVIII at levels below our assay limits of detection, and attempts to isolate these AtT-20 stable clones were not successful. When the BDD-FVIII construct was used in AtT-20 and COS-7 transient transfections, the resulting levels of FVIII activity increased on average 4- and 100-fold, respectively, over similar transfections with the fl-FVIII construct. The reduced ability of the AtT-20 cells to express fl-FVIII that we observed is similar to many reports of the inefficient production of the fl-FVIII protein in other cells $(21,34)$. Although the transiently transfected BDD-FVIII/AtT-20 cells expressed detectable amounts of functional FVIII, the expression levels remained low. To elevate the expression of FVIII, we augmented FVIII mRNA synthesis by the addition of sodium butyrate to the culture media. The expression vector pMT2 used in these experiments uses a promoter that is susceptible to sodium butyrate induction (41). A region in the A2 domain of hFVIII was discovered recently to contain two butyrate-responsive elements, which in the presence of sodium butyrate relieved the transcriptional repression of the FVIII cDNA (42). After sodium butyrate treatment of BDD-FVIII transiently transfected AtT-20 cells, there was a substantial increase in the expression of FVIII, as detected by functional assay of expressed FVIII in treated versus nontreated cells (84.9 vs. 13.6 $\mathrm{mU} / \mathrm{ml}$ of FVIII:C). This treatment greatly enhanced our ability to detect the expression and storage of the FVIII by immu- nofluorescence microscopy. Hence, all the experiments described within this paper have been performed using $B$ domain-deleted FVIII (BDD-FVIII) with sodium butyrate stimulation, unless specifically noted.

Once it was determined that the transfected cells expressed FVIII or vWf, stable AtT-20 clones expressing high levels of vWf (WTvWf/AtT-20) or FVIII (FVIII/AtT-20) were established and characterized. To determine whether correct processing of vWf and FVIII was occurring in AtT-20 cells, the stably transfected cells were metabolically labeled and the media were collected after a 5-h chase. The harvested media were analyzed by immunoprecipitation with anti-vWf and antiFVIII monoclonal antibodies followed by reducing SDSPAGE. The expressed FVIII was detected as primarily single chain with a small amount of processed heavy and light chains

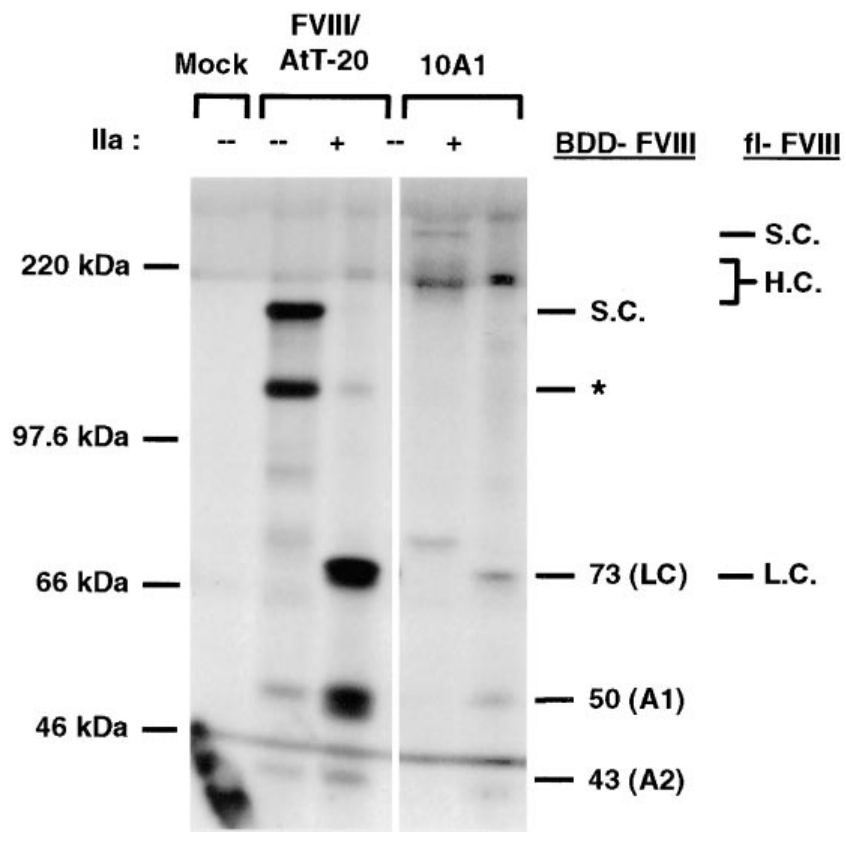

Figure 1. Intracellular processing of FVIII in transfected AtT-20 cells. Plasmid constructs encoding the human FVIII cDNA were transiently transfected into various cell lines, and the resulting protein expression was analyzed after immunoprecipitation. FVIII cDNA constructs (BDD- and fl-FVIII) were stably expressed in AtT-20 and $\mathrm{CHO}$ cells, as indicated above the blot. The cells were metabolically labeled followed by a 5 -h chase, after which the conditioned media were collected and immunoprecipitated with the mAb F-8 (antiFVIII A2 domain-specific) (29) as described in Methods. After elution from the antibody-coupled beads, samples were further treated with thrombin $(+I I a)$ (third and fifth lanes). The samples were then analyzed reduced on $8 \%$ SDS-PAGE gels. The autoradiograph was exposed for $8 \mathrm{~d}$ (fourth and fifth lanes, $14 \mathrm{~d}$ to enhance the weak signal). Mock (first lane) represents media from a negative control AtT-20 cell line $\left(\mathrm{Neo}^{\mathrm{r}}\right)$. FVIII/AtT-20 cells (second and third lanes) were the BDD-FVIII stables created for this study, whereas the 10A1 (fl-FVIII/CHO) cells (fourth and fifth lanes) were created previously (31). The migration of the single chain (S.C.), heavy chain (H.C.), and light chain (L.C.) is noted along the right side for both BDD- and flFVIII. The band marked by the asterisk $(120 \mathrm{kD})$ represents a proteolytic product of the single chain, where the A1 domain $(50 \mathrm{kD})$ has been cleaved by noninactivated serum proteases. The thrombin $(+I I a)$ digested products $(73,50$, and $43 \mathrm{kD})$ are also noted on the right side. ${ }^{14} \mathrm{C}$-labeled protein molecular mass markers are shown on the left side. 


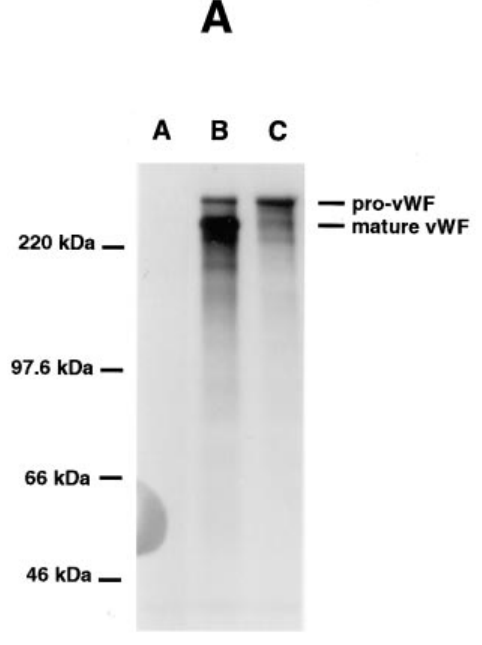

B

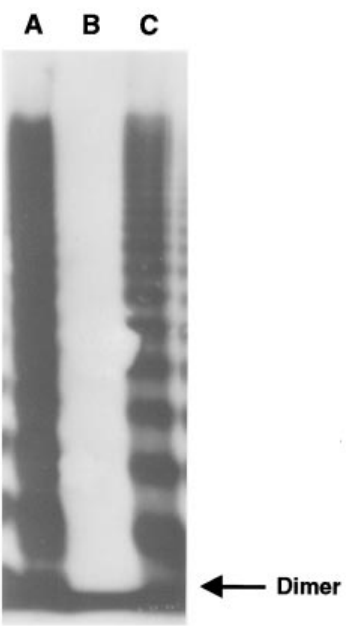

Figure 2. Subunit and multimeric composition of expressed recombinant vWf in AtT-20 cells. (A) Expressed vWf was immunopurified from chase media of metabolically labeled AtT-20 cells after the same experiment described in Fig. 1, except that in these isolates the $\mathrm{mAb} \mathrm{AvW}-1$ was used to capture the labeled vWf for electrophoresis analysis. An autoradiograph (3-d exposure) is shown which displays the different sizes of processed vWf reduced on an $8 \%$ SDS-PAGE gel. Lane $A$ (Mock) represents media from a negative control AtT-20 cell line $\left(\mathrm{Neo}^{r}\right)$. A comparison is shown between WTvWf expressed from labeled WTvWf/AtT-20 cells (lane $B$ ) and pro-vWf expressed from labeled HPPvWf/AtT-20 cells (lane $C$ ). The location of the proand mature vWf bands are marked on the right, while the molecular weight standards are noted on the left. $(B)$ Multimeric analysis of AtT-20 expressed vWf. In this portion of Fig. 2, vWf in the conditioned media has not been metabolically labeled. These samples have been immunoprecipitated with the same AvW-1-coupled Sepharose as in $A$, but analyzed electrophoretically on $3 \%$ agarose gels, as described in Methods. The vWf multimers in lanes $A-C$ were isolated from normal human plasma, mock-transfected AtT-20 cell media, and WTvWf/AtT-20 cell media, respectively. The vWf detected in both cases displays the full multimeric array.

(Fig. 1), and the expressed WTvWf was detected as processed mature vWf with a minor amount of pro-vWf (Fig. $2 A$ ). Since the $\mathrm{B}$ domain-less construct used in this report has the entire B domain excised ( $\Delta 741-1648)$, the major FVIII intracellular cleavage sites at 1313 and 1648 are not present. Hence, the FVIII/AtT-20 stable cell lines express primarily single chain uncleaved FVIII (Fig. 1, second lane), similar to that previously observed by one of us (R.J. Kaufman) when expressing this particular BDD-FVIII construct $(30,43)$. Nonetheless, the FVIII expressed by this construct is functional and thrombin (IIa) cleavage sites remain intact, as demonstrated by the correct-sized thrombin cleavage products that comigrate with the thrombin cleavage products of wild-type FVIII secreted from $\mathrm{CHO}$ cells in Fig. 1 (third and fifth lanes). As shown in Fig. 2 A, the intracellular processing of vWf from pro-vWf to mature vWf occurred normally in the WTvWf-expressing AtT-20 transfected stable cells (lane $B$ ), similar to that previously demonstrated by other investigators using vWf transfected AtT-20 cells $(35,44)$. As expected, the pro-vWf mutant (HPPvWf) showed no intracellular cleavage to mature vWf (Fig. 2

$A$, lane $C$ ). Additionally, the multimeric composition of the AtT-20 expressed WTvWf (Fig. $2 B$, lane $C$ ) was similar to that of plasma vWf (lane $A$ ).

To determine the functionality of the expressed recombinant proteins, vWf secreted by the different AtT-20 stable clones was analyzed by quantitative ELISA and by functional FVIII-binding assays (Fig. 3), while the expressed FVIII was quantified by functional chromogenic FVIII:C activity assays. The levels of vWf expressed by the WTvWf/AtT-20 cells in culture fluctuated between 628 and $1,128 \mathrm{ng} / \mathrm{ml}$ of $\mathrm{vWf}$, and the FVIII expressed by the FVIII/AtT-20 cells (without sodium butyrate treatment) had activity ranging from 74 to 96 $\mathrm{mU} / \mathrm{ml}$ of FVIII:C in assays. To monitor the normal FVIII carrier function of vWf, we compared the quality of the vWf expressed from the different AtT-20 cell lines in FVIII-binding assays. As Fig. 3 demonstrates, the AtT-20-expressed WTvWf captured and bound recombinant FVIII normally. In separate experiments, the stably expressed WTvWf was shown to bind FVIII similar to that of vWf expressed by endogenously producing endothelial cells (see below). As expected, the $2 \mathrm{~N}$ vWD mutant (HPPvWf) expressed by the AtT-20 cells displayed a complete absence of detectable FVIII-binding (shown in Fig.

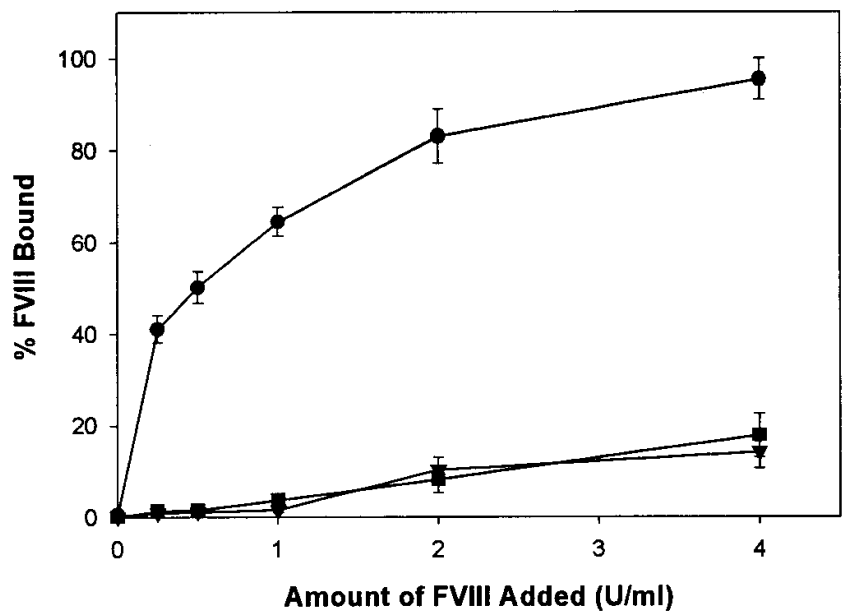

Figure 3. Functional analysis of the FVIII-binding capability of AtT-20 expressed vWf. Secreted recombinant $\mathrm{vWf}$ collected in the conditioned media from three different stable AtT-20 cell lines, WTvWf/ AtT-20 (filled circles), HPPvWf/AtT-20 (filled boxes), and FVIII/ AtT-20 (filled triangles), was captured by immobilized mAb AvW-1 and functionally assayed for FVIII binding as described in Methods. All samples were diluted to $100 \mathrm{ng} / \mathrm{ml}$ of $\mathrm{vWf}$, and reassayed to confirm the diluted concentrations. Various concentrations of rFVIII were added to each sample, listed along the $x$ axis, to generate these curves. The activity of captured rFVIII was then measured by the generation of FX-ase with the Coatest VIII:C/4 kit. This assay was performed four times and the binding results were averaged. All data points have been normalized (percent bound) to the activity of FVIII bound by WTvWf in the presence of $4 \mathrm{U} / \mathrm{ml}$ of rFVIII (100\%). The errors bar represents the standard error of means. The background binding obtained with this assay is shown by the FVIII/AtT-20 samples representing the negative control with no transfected vWf. The small increase in binding at 2 and $4 \mathrm{U} / \mathrm{ml}$ in the negative control FVIII/AtT-20 samples is probably due to the presence of serum (10\% FBS) in the conditioned media. The pro-vWf expressed by the HPPvWf/AtT-20 cells shows no detectable binding of rFVIII above that of the negative control (FVIII/AtT-20 media). 
3), similar to our previous results with HPPvWf expressed by COS-7 cells (32). Both AtT-20-expressed FVIII and vWf displayed normal functional activity in the enzymatic and FVIIIbinding assays, respectively, indicating that the AtT-20 cells possessed the processing pathways necessary for the synthesis and secretion of functional vWf and FVIII.

Immunodetection shows regulated storage of $v W f$ but not FVIII. We visualized the intracellular location of $\mathrm{vWf}$ and FVIII in AtT-20 cells by means of CLSM. In vWf-transfected AtT-20 cells, punctate granules were readily detected by antivWf antibodies (Fig. 4, $A, G$, and $J$ ). The vWf-containing granules ranged in location from midcell towards the apical (lumenal) surface of the cell, with the majority of the granules appearing along the apical cell surface. This granular pattern of vWf storage is consistent with the WPB deposition we have observed in BAEC (see Fig. 7) and HUVEC (not shown) and with previous findings by other investigators for the storage of $\mathrm{vWf}$ in transfected AtT-20 (35, 44), MDCK-II (45), and CV-1 cells (46). When FVIII-expressing stable AtT-20 cells were ob- served with CLSM, only faint diffuse perinuclear staining pattern could be observed (Fig. 4, $D-F$ ), indicating the presence of FVIII in the endoplasmic reticulum, similar to the patterns observed when FVIII was transfected into the nonstorage cell line COS-7 (data not shown). FVIII-producing AtT-20 cells have been tested with 15 different monoclonal and polyclonal anti-human FVIII antibodies using immunofluorescence staining, and none detected FVIII localized to granules. One of these $\mathrm{mAb}$ is MBC 103.3 which has been used for the immunodetection of FVIII in this report. Similar immunofluorescence microscopy results were obtained with transfected cells not treated with sodium butyrate, although the level of FVIII fluorescent detection in these cells was weaker. The pattern of $\mathrm{vWf}$ and FVIII intracellular staining was not altered by the addition of sodium butyrate to the media. Thus, unlike vWf, there is no innate storage of FVIII in the AtT-20 cells.

Because we were analyzing transient transfections with variable transfection efficiency, each immunofluorescently stained slide was thoroughly examined. For each immunolabeling ex-
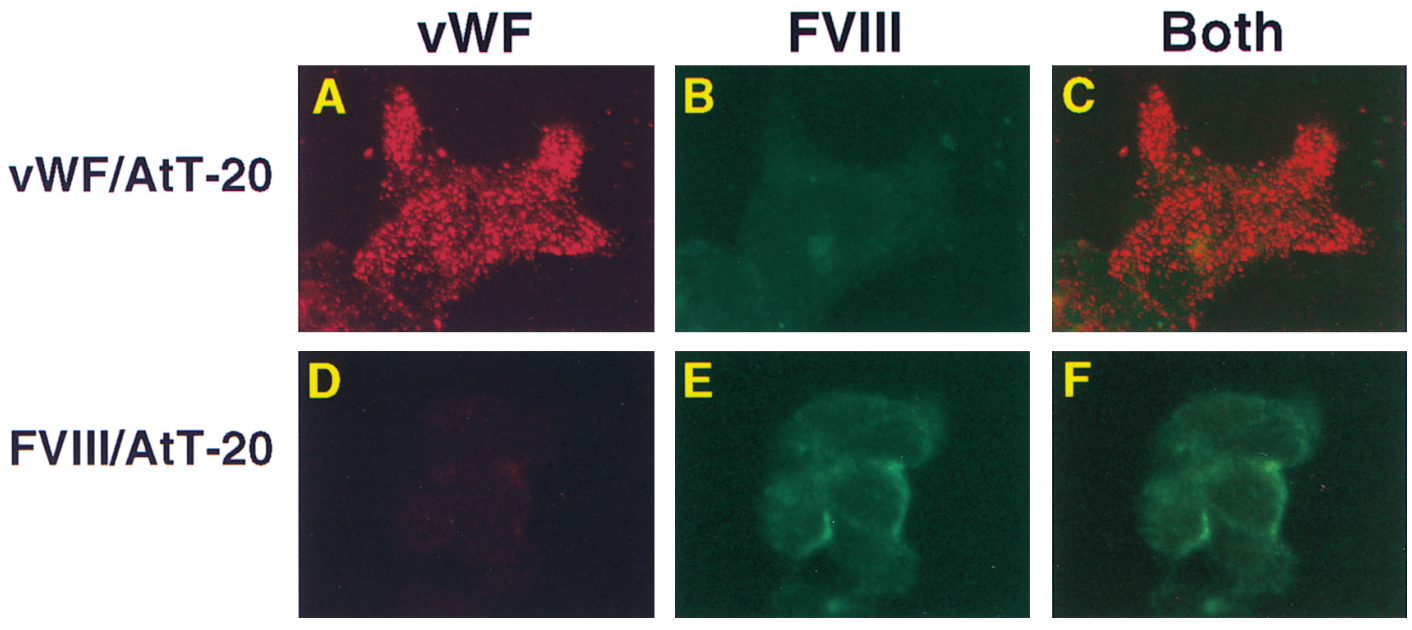

FVIII/AtT-20

+ WTvWF
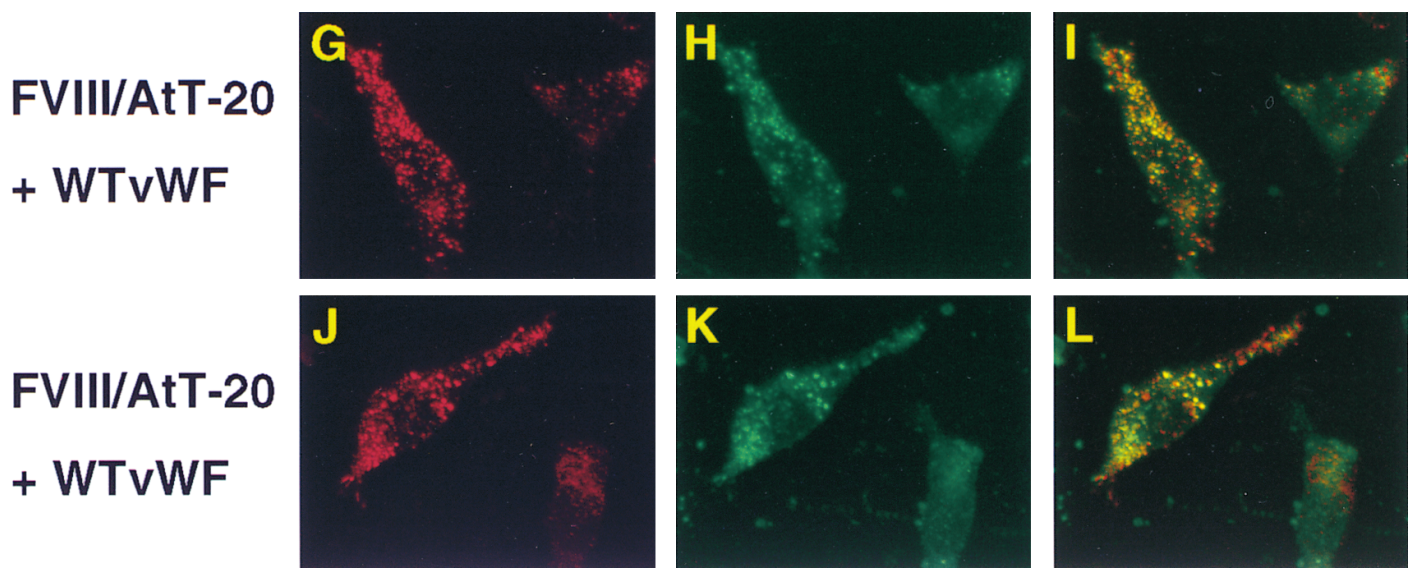

Figure 4. Intracellular distribution of vWf and FVIII in AtT-20 cells. Stable AtT-20 cells were transiently transfected with either pCI-Neo or WTvWf plasmids. After $72 \mathrm{~h}$, cells were fixed, permeabilized, and double-labeled with an anti-FVIII mAb (MBC 103.3) (detected with FITCconjugated donkey anti-mouse IgG) and a polyclonal antibody to human vWf (detected with TXR-conjugated donkey anti-rabbit IgG). Images shown are the stacked confocal projections representative of independent secondary transient transfections. Mock transfections with pCI-Neo of WTvWf/AtT-20 cells $(A-C)$ and FVIII/AtT-20 cells $(D-F)$ show staining of only one of the proteins. In contrast, transfections with the WTVWf plasmid of FVIII/AtT-20 cells ( $G-I$ and $J-L)$ show colocalization of the two proteins. As labeled above each column, the first column shows vWf detection by TXR (in red), the second column shows FVIII detection by FITC (in green), and the third column shows the merged TXR/FITC images where colocalization is shown in yellow. Cells were viewed and digitally photographed with a Bio-Rad MRC 600 confocal microscope with a $\times 60$ objective, and the field zoomed $\times 2.5$ before $Z$-series construction $(\times 2,512$ total enlargement $)$. 
periment, at least 1,000 cells per slide were assessed for immunofluorescence detection using manual epifluorescence microscopy before CLSM imaging. Figs. 4, 6, and 7 contain randomly selected positive-staining cells that are representative of the positive cells seen in the entire transfection as visualized by CLSM. The confocal microscopy pictures shown in these figures are the stacked three-dimensional projection images (TXR and FITC channels and merged views) from transient transfections of FVIII/AtT-20 stable or BAEC cell lines. The images shown in Figs. 4 and 6 are the results of separate secondary transfections of AtT-20 stable cell lines. Negative control plasmids (pCI-Neo) were used to demonstrate that FVIII storage or lack of it was not an artifact of transfection conditions. Although we are showing dual fluorescent pictures in this report, these are computer-assigned colors based on the intensity of the overlap of the two channels. The individual fluorescent components were detected and digitally processed using single wavelength excitation filters on the CLSM. As a result, the immunodetection of FVIII antigens inside vWf-containing granules was not a result of crossover from intensely staining vWf in the TXR channel into the FITC channel during laser scanning and data collection. As an additional control in other experiments, the secondary antibody-fluorochrome assignment was reversed and the same intracellular patterns for vWf (storage) and FVIII (nonstorage) were observed (data not shown).

$v W f$ functions as an intermolecular chaperone for FVIII. To analyze the role of vWf in the FVIII secretory pathway, we transfected the AtT-20 cell lines stably expressing vWf or FVIII with FVIII or vWf constructs, respectively, to obtain a subpopulation of cells expressing both proteins. These experiments were performed to address whether the synthesis of vWf affected the intracellular trafficking of FVIII. When these transfected cells were analyzed by dual immunofluorescence, the appearance of the subcellular FVIII had been shifted from purely cytoplasmic into a pattern of both granular deposition and cytoplasmic staining. The change is clearly visible in the FITC-only projection images when vWf transfected FVIII/ AtT-20 cells are compared with the mock transfections (pCINeo) of the FVIII/AtT-20 cells (Fig. $4, H$ and $K$ vs. $E$ ). Merging the separate projection images obtained from FITC-only and TXR-only emission detection, we observed that double transfected cells contained yellow granules indicating colocalized compartmentalized storage of FVIII and vWf (Fig. 4, compare $I$ and $L$ with $C$ and $F$ ). We conclude that transient transfection of WTvWf cDNA into FVIII/AtT-20 cells caused a significant portion of the nascent FVIII to undergo granulespecific storage which was detectable within all vWf-containing granules (Fig. 4, $G-L$ ).

Specific FVIII intracellular interaction with $v W f$. We next investigated the nature of these FVIII-vWf intracellular interactions by repeating the FVIII/AtT-20 secondary transfections, but this time with vWf plasmids possessing defective FVIII binding. The plasma and intracellular avidities for FVIII of known type $2 \mathrm{~N}$ vWf mutants were compared. Two different binding defects have been studied in this report: HPPvWf and R91Q vWf, both encoding type $2 \mathrm{~N}$ vWD mutations. When transiently transfected into FVIII/AtT-20 cells, neither vWf mutant appears to affect the constitutive secretion of FVIII (Fig. 5). While the transfection efficiency varied from experiment to experiment, we never observed a significant reduction $(>50 \%)$ of FVIII secretion after transient transfection of ei-

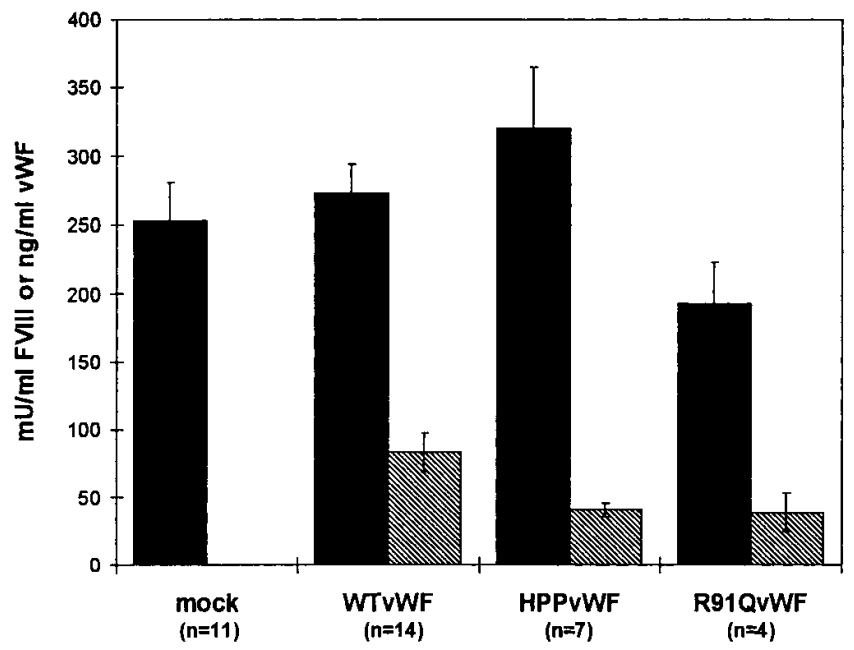

Figure 5. Comparison of the FVIII and vWf expression levels in vWf transfected FVIII/AtT-20 cells. Analysis of the secreted proteins expressed by the stable FVIII/AtT-20 cells, after transfection (72 h), was performed after each series of cell transfection before the immunofluorescence stainings. The conditions remained the same for all the transfections, with the conditioned media harvested after $24 \mathrm{~h}$ of sodium butyrate treatment. The plasmids used in the transfection are listed along the $x$ axis. "Mock" refers to the transfection of the vector, pCI-Neo, into the cells as a negative control. The results represent the mean protein levels from eight transient transfection experiments used to obtain immunofluorescent images shown in this report. The total number of independent plates listed below each plasmid type (as $n$ ). The average mean FVIII activity (solid bars) and the average mean vWf (striped bars) are shown \pm SEM. The values shown have been calculated as $\mathrm{mU} / \mathrm{ml} / \mathrm{d} / 10^{6}$ cells (FVIII:C) and $\mathrm{ng} / \mathrm{ml} / \mathrm{d} / 10^{6}$ cells (vWf:Ag), and are shown along the dual $y$ axis.

ther WT or $2 \mathrm{~N} v W f$ constructs (Fig. 5). This suggests that the presence of vWf inside the cells did not cause a detectable shift in the FVIII secretory pathway from constitutive release to storage in the regulated secretory pathway. The shift to regulated storage of FVIII most likely represents a small fraction of the nascent FVIII since the levels of constitutive secretion of FVIII appear unaltered. However, by immunofluorescence staining, the effect of intracellular vWf-FVIII interactions on the secretory pathway of FVIII was apparent. Expression of a severe type $2 \mathrm{~N}$ vWf (HPPvWf) construct in FVIII/AtT-20 cells failed to direct nascent FVIII into storage granules (Fig. 6, compare $B$ with $E$, and $C$ with $F$ ), even though the synthesized pro-vWf was stored normally in granules (Fig. 6, $A$ and $D$ ). The storage of uncleaved pro-vWf (HPPvWf) detected in AtT-20 secretory granules during this study agrees with the report of pro-vWf transfection of $\mathrm{CV}-1$ cells by Voorberg et al. (46), but conflicts with the report by Journet et al. for pro-vWf transfection of AtT-20 cells (44). This may be due to their use of a different pro-vWf mutant (Gly763 mutant) than our HPPvWf clone. Compared with WTvWf transfections, reduced FVIII storage was also seen with a moderately severe type $2 \mathrm{~N}$ vWf (R91Q vWf) when transiently transfected with FVIII/ AtT-20 cells. In most of the transient transfections with this construct there was no colocalization detected (Fig. 6, $G-I$ ), but several cells did display an occasional FVIII granule, suggesting FVIII colocalization in a minor number of vWf gran- 


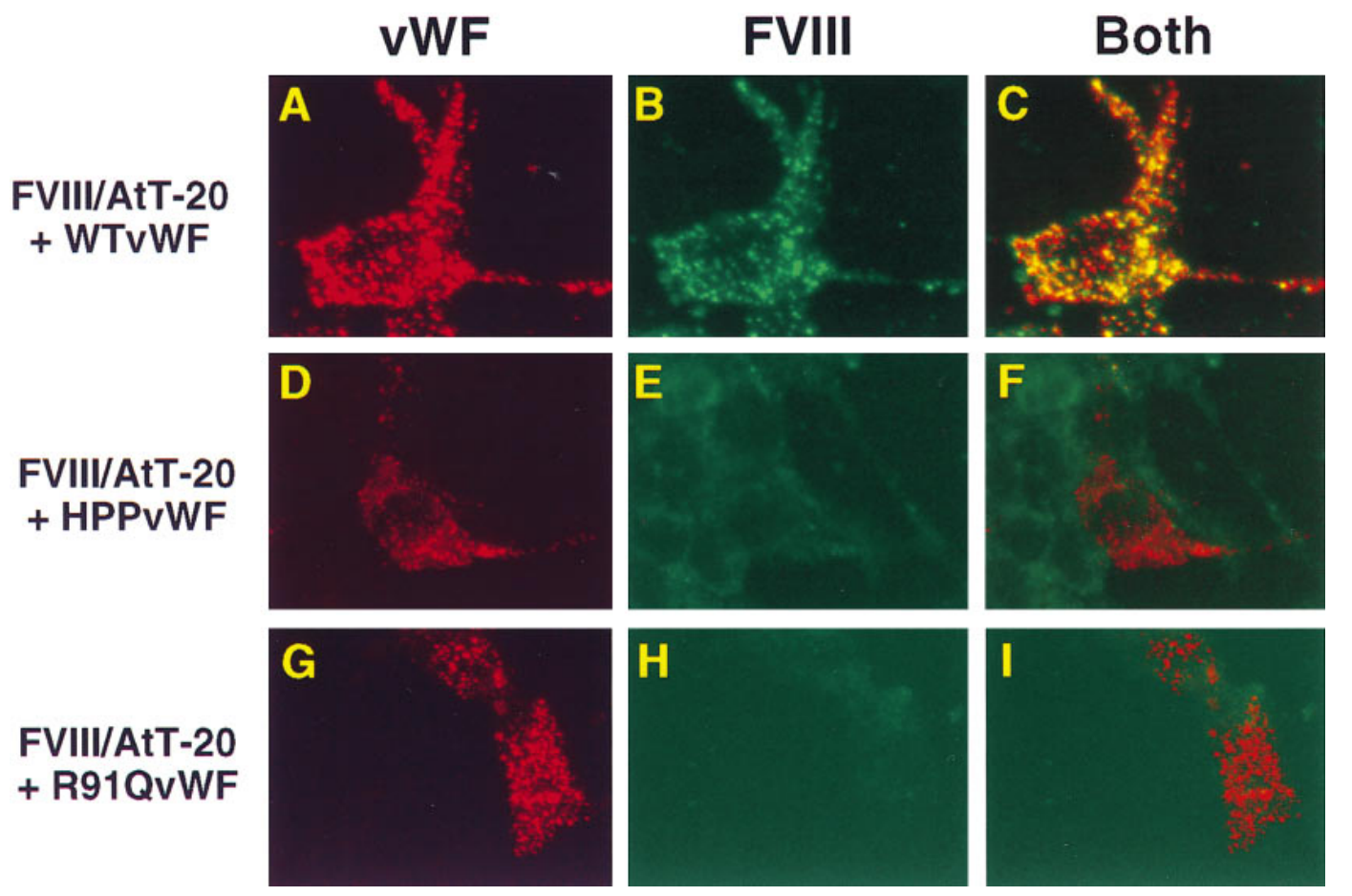

Figure 6. vWf-dependent storage of FVIII in intracellular vesicles. Stable FVIII/AtT-20 cells (all panels) were transiently transfected with either WTvWf $(A-C)$, HPPvWf (2N vWD) $(D-F)$, or R91Q vWf (2N vWD) $(G-I)$ plasmids, as previously noted. Afterwards, the cells were fixed, permeabilized, and dual-labeled with monoclonal anti-FVIII antibody MBC 103.3 and a polyclonal anti-vWf antibody, as described in Fig. 4 . $\times 2,512$ total enlargement. Dual fluorescent detection is shown in the color merges labeled as "Both" in the far right column.

ules (not shown). These data demonstrate that the granular storage of FVIII is vWf dependent and not merely a result of vWf storage granular formation.

Since the AtT-20 cells are actively involved in the synthesis and storage of the prohormone ACTH (33), we performed additional analysis of the transfected FVIII/AtT-20 cells by including slides incubated with anti-FVIII and anti-ACTH antibodies in several of the immunofluorescence staining series. Confocal microscopic analysis of these transfected cells revealed the expected granular deposits of ACTH. No colocalization of FVIII in ACTH-containing granules was observed in the immunolabeled FVIII/AtT-20 cells (data not shown). In contrast, transient transfection of WTvWf plasmids into these FVIII/AtT-20 cells demonstrated FVIII storage with vWf but neither protein with ACTH. This confirms the finding of Wagner et al. (35) that transfected vWf and endogenous ACTH are sorted to separate secretory granules in AtT-20 cells. The nascent FVIII molecules are not shunted to random storage granules, but only to those containing vWf with intact FVIII binding domains. We have never observed immunofluorescence detection of FVIII-only storage granules in transfected AtT-20 cells. Additionally, the presence of vWf extracellularly (either secreted by cells or the addition of purified vWf) in the culture media did not increase the amount of FVIII in granular storage. We have cocultured the two AtT-20 stable lines (WTvWf/AtT-20 and FVIII/AtT-20) together in 35-mm dishes. After several days, the cell lines remained distinct upon viewing the fixed cells with CLSM. In neither cell line in the cocultures was FVIII detected within storage granules, and no uptake of vWf was observed in the cytoplasm of these FVIII/
AtT-20 cells (data not shown). Taken together, these results indicate that the storage of FVIII in cells is specifically related to the synthesis of $\mathrm{vWf}$ in the same cell.

FVIII can be sorted into endothelial WPB. In vivo, the primary cell synthesizing, storing, and releasing $\mathrm{vWf}$ is the endothelial cell. Therefore, we studied FVIII trafficking in endothelial cells, such as the nonembryonic BAEC. Like other endothelia, the BAEC display readily detectable WPB (47), but unlike HUVEC the BAEC are more easily transfected. To demonstrate that bovine vWf secreted by the BAEC cultures could interact with human FVIII, additional FVIII-binding assays were performed as shown above (see Fig. 3). We have determined that antibody-captured bovine vWf bound human rFVIII similar to that of AtT-20- and HUVEC-expressed WTvWf (using $2 \mathrm{U} / \mathrm{ml}$ of FVIII, the values were $120 \%$ vs. $90 \%$ and $100 \%$, respectively). Low passage BAEC have been transfected with the BDD-FVIII plasmid and the resulting intracellular distribution pattern of FVIII was studied by CLSM. Immunofluorescence staining of nontransfected BAEC detected neither the presence nor storage of intracellular FVIII, and FVIII:C activity assays of BAEC culture media failed to detect endogenous FVIII activity. After transient transfection with FVIII, BAEC produced measurable levels of FVIII activity $(4-8 \mathrm{mU} / \mathrm{ml})$ in the conditioned media and immunodetectable FVIII inside the cells. Based upon the number of immunodetectable FVIII transfected cells, the transient transfection efficiency of this FVIII construct appears to be similar in both AtT-20 and BAEC cells ( 1-2\% efficiency). In contrast, the readily transfectable nonstorage COS-7 cells, when transiently transfected with BDD-FVIII ( 30\% efficiency), consistently 
produced high levels of FVIII in the conditioned media (200$430 \mathrm{mU} / \mathrm{ml}$ of FVIII). Transient transfections of BAEC with BDD-FVIII plasmids demonstrated immunodetectable granular storage of FVIII, similar to that seen in AtT-20 transfections. As shown in Fig. 7, nascent FVIII colocalized with endogenously produced $\mathrm{vWf}$ in storage vesicles, displayed here by the yellow pixels in the FITC/TXR merged images (Fig. 7, bottom). Some cytoplasmic staining of FVIII was detected in the transfected endothelial cells, but only in cells that also displayed vesicular storage of FVIII (Fig. 7, middle). The cells


Figure 7. Colocalization of transfected FVIII with vWf in endothelial cell WPB. BAEC were cultured in LabTek chamber slides (Fisher Scientific, Itasca, IL), and transfected as previously noted. Afterwards, the cells were fixed, permeabilized, and dual-labeled with monoclonal anti-FVIII antibody MBC 103.3 and a polyclonal antivWf antibody, as described in Fig. 4. The top panel shows vWf detection with TXR (in red). The middle panel shows FVIII detection with FITC (in green). The bottom panel shows the confocal merge of the TXR/FITC images. $\times 2,512$ total enlargement. shown in Fig. 7 are representative of the degree of colocalization of FVIII and vWf in these endothelial cell transfections, with clear differences between transfected and surrounding cells. The BAEC used in these transfection experiments retained their normal complement of WPB, which continued to exhibit positive immunostaining for vWf (Fig. 7 top).

Since DDAVP stimulates the release of stored vWf and possibly FVIII, we further investigated whether the WPB-like granules in the transfected AtT-20 and BAEC cells could be stimulated in an analogous manner releasing stored $\mathrm{vWf}$ and FVIII. Although inefficient, the cAMP analogue 8-Br-cAMP has been shown to function in AtT-20 cells as a secretagogue causing stimulated release of stored granular proteins, such as ACTH, insulin, and vWf $(33,35,48)$. However, confocal microscopic examination of the transfected AtT-20 cells showed little difference in the vWf/FVIII granules between the 8-Br-cAMP-treated and nontreated cells. Hence, we found it necessary to examine the release potential in endothelial cells, where stimulated release of granular components such as vWf by PMA and histamine has been demonstrated previously (40). Although the number of cells successfully transfected was low in the BAEC-FVIII transient transfections, the transfected BAEC cells consistently displayed granular storage of colocalized FVIII and vWf when examined by CLSM. Upon agonist stimulation with either PMA or histamine, cells with immunodetectable FVIII/vWf granules could no longer be identified (data not shown). There was a parallel loss of both vWf and FVIII from storage granules in the PMA-treated transient transfected BAEC. Attempts to quantify the amount of FVIII released by agonist stimulation of the transfected cells have been hampered by the low number of FVIII transfected BAEC. FVIII activity assays of PMA- or histaminetreated cell conditioned media showed minimal amounts of FVIII above the sensitivity of the assay. Visually, the FVIII, shunted into regulated storage by the bovine vWf, appears to have been released in parallel with vWf from the WPB after stimulation with PMA. This further supports the hypothesis that FVIII storage can occur in the WPB, forming a releasable vWf-FVIII in vivo storage pool when both proteins are expressed in endothelial cells. The focus of this initial investigation was FVIII trafficking. The question of regulated granule release must await further experiments with improved transfection efficiencies.

\section{Discussion}

The tissue distribution of vWf has been studied extensively and the synthesis is limited to the vascular endothelium and megakaryocytes (14), where it is stored in endothelial cell WPB and platelet $\alpha$-granules, respectively (14). In contrast, the site of FVIII synthesis is not clearly established. Although mRNA for FVIII has been detected in many tissues $(22,23)$, the cellular site of synthesis within these tissues is not well defined. Tissue expression of FVIII has also been studied through organ and tissue transplantation which demonstrates that in humans and dogs the production of FVIII occurs in the liver, spleen, and lymph nodes (24-28). While mRNA for human FVIII has been identified in hepatocytes (22), the plasma level of FVIII, unlike other hepatocyte-synthesized proteins, is elevated rather than depressed in end-stage liver failure (2). Cellular staining for FVIII is complicated by the recognized low levels of protein synthesis and subsequent difficulty with im- 
munostaining $(8,23)$. Although the clinical therapy of patients with mild hemophilia or vWD with the drug DDAVP results in a marked rise in both FVIII and vWf proteins in plasma (3-6), no site of intracellular storage for FVIII has been demonstrated. The endothelial cell appears to be the primary source of this released vWf (12). The coexpression of vWf and FVIII in tissue culture has been carried out previously in $\mathrm{CHO}$ cells but not in a cell line with a defined storage pathway (49). Wagner and co-workers have studied synthesis of $\mathrm{vWf}$ in the model cell line AtT-20 extensively and demonstrated intracellular processing and sorting to be similar to that found in vascular endothelium $(35,39)$. The potential intracellular interactions between FVIII and vWf and their potential roles in generating an intracellular storage pool of FVIII are important issues to define. Furthermore, since vascular endothelium may be one of the logical sites for gene therapy of hemophilia A, understanding how FVIII functions intracellularly in a cell producing vWf has added significance.

The concentration of FVIII in plasma is quite low, with estimates ranging from 100 to $200 \mathrm{ng} / \mathrm{ml}$ (22). The low levels of FVIII expression in vitro after transfection with the human FVIII gene have been ascribed to low levels of FVIII mRNA production (22) and inefficient secretion that correlates with interaction with the protein chaperone, $\operatorname{BiP} / \operatorname{GRP} 78(34,41)$. These effects can be circumvented using a FVIII gene from which the coding region for the B domain has been removed, resulting in a marked increase in FVIII synthesis by the transfected cells $(30,43)$. The expressed recombinant B domainless FVIII remains fully functional. B domain-deleted FVIII can correct the cuticle bleeding time in the canine model of hemophilia A (43), and is generally thought to be as effective as full-length FVIII. In addition, a B domain deletion molecule (ReFactor, FVIII-SQ) (Pharmacia, Columbus, OH) is being used currently in European and American clinical trials for treating patients with hemophilia A. Most efforts toward gene therapy for hemophilia A use B domain-deleted FVIII because of its increased expression level. For these reasons we have used BDD-FVIII in our studies and postulated that BDD-FVIII would traffic inside the cell in a manner analogous to fl-FVIII. AtT-20 cells transfected with a B domaindeleted FVIII construct (BDD-FVIII) resulted in a greatly increased level of FVIII expression over that of fl-FVIII transfected in the same cell line. This increased level of synthesis permitted detection by both activity assays and immunostaining. The production of FVIII was further enhanced through creating stable cell lines in which all cells were synthesizing FVIII. Our studies demonstrate that BDD-FVIII is appropriately processed in AtT-20 cells and results in a FVIII protein that has a specific activity similar to wild-type recombinant FVIII.

As described above, the AtT-20 cell line is derived from a mouse pituitary tumor that possesses both constitutive as well as regulated secretion pathways, and has been used by a number of investigators to study the sorting of proteins including insulin, trypsinogen, and vWf into secretory vesicles $(33,35$, 48). The coexpression of vWf and FVIII has been reported previously in CHO cells (49); however, these cells do not produce secretory granules and are therefore incapable of mimicking the interactions that may occur in the presence of $\mathrm{vWf}$ targeted to the regulated pathway. As expected, transfection of AtT-20 cells with vWf resulted in the specific storage of vWf in storage organelles thought to be analogous to the WPB in endothelial cells. In contrast, AtT-20 cells transfected with FVIII exhibit only cytoplasmic staining with no specific storage granule identified (Fig. 4). Thus, the FVIII protein does not possess inherent signals for regulated granular storage.

To study the effect of vWf on intracellular trafficking of FVIII, the cDNA for both proteins needed to be inserted into AtT-20 cells. Transfection of a full-length vWf expression vector into a stable AtT-20 cell line producing FVIII altered the trafficking of FVIII so that it was stored in the same storage granules as vWf. This demonstrates a novel molecular chaperone function for vWf, whereby it diverts a portion of FVIII from constitutive secretion to a regulated pathway of storage. To our knowledge, this is the first demonstration of such a chaperone mechanism for a secreted protein and may have important implications for cellular storage of other proteins.

The strong interaction between vWf and FVIII is established clearly in the extracellular environment and has been characterized extensively in plasma (for reviews see references 14 and 21). In fact, if patients with severe (type 3) vWD are treated with vWf concentrates, the level of plasma FVIII gradually rises from nearly undetectable levels to maximal (nearly normal) levels at $24 \mathrm{~h}$ after the infusion (50). The time course of this interaction is in marked contrast to the nearly instantaneous rise of both proteins after the administration of DDAVP in normal individuals or patients with mild vWD or hemophilia A (3-6). Such a response suggests the possibility of costorage of both proteins. To further understand the intracellular relationships between vWf and FVIII, we explored the intracellular interactions when mutant vWf molecules are used in our system. Our laboratory, as well as other laboratories, has identified and characterized mutations causing type $2 \mathrm{~N}$ vWD in which a molecular defect of vWf results in a protein with reduced or undetectable binding of FVIII $(19,20,32)$. In this study, we used two such mutant vWf molecules: the first with a R91Q mutation, the most common basis of type $2 \mathrm{~N}$ vWD (51); and the second with a HPPvWf mutation, a rare defect with no cleavage of the vWf propolypeptide. Prior research has characterized this latter vWf mutation with nearly absent FVIII binding (52) while the former mutation has markedly reduced binding to FVIII (32). When the AtT-20 cells stably expressing FVIII were secondarily transfected with these Type $2 \mathrm{~N}$ mutants, we found a dramatic reduction in FVIII granular storage with the R91Q mutation and nearly absent granular storage of FVIII with the mutation causing persistence of pro-vWf (Fig. 6). Thus, the avidity of these two vWf molecules in the extracellular milieu for FVIII appears similar to that which we have observed intracellularly when both vWf and FVIII are being synthesized and are available for storage.

Intracellular processing of $\mathrm{vWf}$ is a complex series of events. Studies have demonstrated the order of vWf processing to be synthesis of the pro-vWf molecule, COOH-terminal dimerization, glycosylation, sulfation, $\mathrm{NH}_{2}$-terminal multimerization, propeptide cleavage, and then secretion or granular storage $(14,35,39,44,53)$. Propolypeptide cleavage of vWf has been localized to the TGN occurring before the formation of the secretory granule (39); however, the propolypeptide and mature vWf remain noncovalently associated (39) with both residing in secretory granules (54). Since FVIII cannot bind to a pro-vWf molecule from which the propolypeptide has not been cleaved (55), and since FVIII can be stored in the secretory granule together with vWf, our studies suggest that FVIII must have access to the (propeptide-cleaved) mature vWf be- 
fore granule formation. In addition, FVIII binding to vWf requires sulfation of Tyr1680 in FVIII and this modification also occurs within the TGN (56). Therefore, association of FVIII with vWf appears to be the final step before vWf spacial segregation into secretory granules, and would suggest that the order of processing events for $\mathrm{vWf}$ in the TGN is: multimerization, propolypeptide cleavage, FVIII association, and then secretory granular storage.

We have used the AtT-20 cell line so that we might be able to study storage/secretion while manipulating the genes for vWf and FVIII independently. Obviously, the AtT-20 cell is not the normal cell of synthesis for either protein, thus we wanted to explore the relevance of FVIII synthesis by a cell in which vWf is normally synthesized. When the human FVIII gene was transfected into BAEC, it underwent identical compartmental trafficking to that observed in AtT-20 cells, and was stored together with $\mathrm{vWf}$ in granules. In the BAEC model, all cells are producing and storing vWf, and only a small number of these cells are secondarily transfected with the FVIII gene. Cells producing FVIII were identified both by their cytoplasmic staining as well as their granular staining (Fig. 7). While some vWf granules may have been produced before transfection with the FVIII, the majority of immunodetectable granules exhibited colocalization of both vWf and FVIII. Thus, this intracellular association occurs both with the model AtT-20 cell line as well as with endothelial cells normally producing endogenous vWf, and this suggests that such interactions could occur in vivo.

Our observations are particularly relevant to the gene therapy of hemophilia A where the endothelium or hematopoietic stem cell may be one of the targets chosen for gene targeting. If FVIII is produced in vascular endothelium or megakaryocytes, we would anticipate that FVIII would be released both into the extracellular milieu constitutively and in addition partitioned with vWf into granular storage sites that might be subsequently released by vascular injury or by the administration of DDAVP. Such intracellular stores of FVIII and vWf may offer a clear advantage for endothelial cell targeting by protecting the nascent FVIII from extracellular proteolysis and increasing its local concentration at sites of vascular injury. Whether the intracellular storage of FVIII reduces the amount of constitutively secreted FVIII is not clear. Although our studies were not specifically designed to address this question, we found that the level of FVIII activity in the conditioned media was not significantly decreased when FVIII underwent regulated storage (Fig. 5). This may be due, in part, to improved intracellular processing of FVIII in the presence of $\mathrm{vWf}$, as has been shown in transfected $\mathrm{CHO}$ cells $(30,49)$.

While the AtT-20 cell is an excellent cell to study intracellular trafficking, it is not ideal for studies of vWf release, as discovered in studies by Wagner and others (for review see reference 57). Our experiments have demonstrated a similar unremarkable twofold increase in vWf levels upon release by 8-Br-cAMP from AtT-20 transfected cells, and as such the increases in FVIII due to release from FVIII/WTvWf storage granules in AtT-20 cells were found to be insignificant. Studies are in progress using a different transfection strategy to produce endothelial cells with more meaningful levels of transfection efficiency.

Whether the mechanisms described in this manuscript explain the intracellular stores of FVIII that are DDAVP releasable is not clear. Endothelial cells in tissue culture have not been demonstrated to have stores of FVIII; however, relevant cytokines have not been studied exhaustively for their potential effect on FVIII synthesis. Furthermore, since endothelial cells from various vascular beds exhibit different phenotypes (9) with respect to their local environment, not all endothelial cells may possess the capacity to produce both proteins. Since the most conclusive studies with tissue transplantations in hemophilia A have been with reticuloendothelial tissue (24-28), endothelial cell populations from these organs would be an obvious choice for future study. Furthermore, the potential for endothelial cell targeting in the gene therapy of hemophilia A warrants a need for greater understanding of the intracellular interaction between these two proteins within the endothelial cell secretory pathways.

Our studies demonstrate that the trafficking of FVIII from the TGN to vesicular storage is vWf dependent and that specific mutations in $\mathrm{vWf}$ affect this trafficking and storage in a manner analogous to the interaction of these proteins in plasma. This represents a newly recognized chaperone function for an intracellular protein and such interactions permit the storage of a protein not normally targeted for such storage by itself. Since FVIII does not bind to vWf until the propolypeptide is cleaved, the presence of FVIII in these storage granules confirms that the propolypeptide is cleaved from the vWf multimers before final formation of the storage granule (39). The intracellular storage of FVIII may be relevant to gene therapy protocols that propose to target vascular endothelium or stem cells with the FVIII gene. Utilization of this regulated secretory pathway may increase the bioavailability of FVIII at the sites of endothelial and/or platelet perturbation. This mechanism may also account for the site of DDAVP-releasable FVIII; however, confirmation of this hypothesis will require more intensive study.

\section{Acknowledgments}

We thank Mr. B. Schroeder and Dr. J. Neitz (Medical College of Wisconsin) for help with confocal microscopy and Dr. P.J. Newman (The Blood Center of Southeastern Wisconsin) for his critical review of this manuscript.

This study was supported by National Institutes of Health training grant HL-07209 (J.B. Rosenberg) and National Institutes of Health grants HL-53777 and HL-52173 (R.J. Kaufman), HL-50520 (P.A. Kroner), and HL-44612 and HL-33721 (R.R. Montgomery).

\section{References}

1. Mannucci, P.M. 1988. Desmopressin: a nontransfusional form of treatment for congenital and acquired bleeding disorders. Blood. 72:1449-1455.

2. Montgomery, R.R., and B.S. Coller. 1994. von Willebrand disease. In Hemostasis and Thrombosis: Basic Principles and Clinical Practice. 3rd ed. R.W. Colman, J. Hirsh, V.J. Marder, and E.W. Salzman, editors. J.B. Lippincott Co., Philadelphia. 156-157.

3. Hashemi, S., E.S. Tackaberry, D.S. Palmer, G. Rock, and P.R. Ganz. 1990. DDAVP-induced release of von Willebrand factor from endothelial cells in vitro: the effect of plasma and blood cells. Biochim. Biophys. Acta. 1052:63-70.

4. Casonato, A., D. Dannhauser, E. Pontara, A. Bertomoro, B. Orazi, P. Zerbinati, and A. Girolami. 1996. DDAVP infusion in haemophilia A carriers: different behaviour of plasma factor VIII and von Willebrand factor. Blood Coagul. Fibrinolysis. 7:549-553

5. Lethagen, S. 1994. Desmopressin (DDAVP) and hemostasis. Ann. Hematol. 69:173-180.

6. Mannucci, P.M., M.T. Canciani, L. Rota, and B.S. Donovan. 1981. Response of factor VIII/von Willebrand factor to DDAVP in healthy subjects and patients with hemophilia and von Willebrand's disease. Br. J. Haematol. 47: 283-293.

7. Cattaneo, M., L. Simoni, A. Gringeri, and P.M. Mannucci. 1994. Patients 
with severe von Willebrand disease are sensitive to the releasing effect of DDAVP: evidence that the DDAVP-induced increase in plasma factor VIII is not secondary to the increase in plasma von Willebrand factor. Br. J. Haematol. 86:333-337.

8. Kadhom, N., C. Wolfrom, M. Gautier, J.P. Allain, and D. Frommel. 1988. Factor VIII procoagulant antigen in human tissues. Thromb. Haemostasis. 59: 289-294.

9. Belloni, P.N., D.H. Carney, and G.L. Nicolson. 1992. Organ-derived microvessel endothelial cells exhibit differential responsiveness to thrombin and other growth factors. Microvasc. Res. 43:20-45.

10. Wagner, D.D., J.B. Olmsted, and V.J. Marder. 1982. Immunolocalization of von Willebrand protein in Weibel-Palade bodies of human endothelial cells. J. Cell Biol. 95:355-360.

11. D'Angelo, A., A. Capitanio, J.B. Smith, C. Valsecchi, and P.M. Mannucci. 1983. Effect of des-amino-D-arginine vasopressin (DDAVP) on plasma levels of platelet and endothelial cell release products. Thromb. Haemostasis. 49:64-65.

12. Takeuchi, M., H. Nagura, and T. Kaneda. 1988. DDAVP and epinephrine-induced changes in the localization of von Willebrand factor antigen in endothelial cells of human oral mucosa. Blood. 72:850-854.

13. Meyer, D., and J.-P. Girma. 1993. von Willebrand factor: structure and function. Thromb. Haemostasis. 70:99-104.

14. Wagner, D.D. 1990. Cell biology of von Willebrand factor. Annu. Rev. Cell Biol. 6:217-246.

15. Halban, P.A., and J.-C. Irminger. 1994. Sorting and processing of secretory proteins. Biochem. J. 299:1-18.

16. Burgess, T.L., and R.B. Kelly. 1987. Constitutive and regulated secretion of proteins. Ann. Rev. Cell Biol. 3:243-293.

17. Sporn, L.A., V.J. Marder, and D.D. Wagner. 1989. Differing polarity of the constitutive and regulated secretory pathways for von Willebrand factor in endothelial cells. J. Cell Biol. 108:1283-1289.

18. Sporn, L.A., V.J. Marder, and D.D. Wagner. 1987. von Willebrand factor released from Weibel-Palade bodies binds more avidly to extracellular matrix than that secreted constitutively. Blood. 69:1531-1534.

19. Ginsburg, D., and J.E. Sadler. 1993. von Willebrand disease: a database of point mutations, insertions, and deletions. Thromb. Haemostasis. 69:177-184.

20. Kroner, P.A., K.D. Friedman, S.A. Fahs, J.P. Scott, and R.R. Montgomery. 1991. Abnormal binding of Factor VIII is linked with the substitution of glutamine for arginine 91 in von Willebrand factor in a variant form of von Willebrand disease. J. Biol. Chem. 266:19146-19149.

21. Kaufman, R.J. 1992. Biological regulation of factor VIII activity. Ann. Rev. Med. 43:325-339.

22. Wion, K.L., D. Kelly, J.A. Summerfield, E.G.D. Tuddenham, and R.M. Lawn. 1985. Distribution of human VIII mRNA and antigen in human liver and other tissues. Nature. 317:726-728.

23. Zelechowska, M.G., J.A. van Mourik, and T. Brodniewicz-Proba. 1985. Ultrastructural localization of factor VIII procoagulant antigen in human liver hepatocytes. Nature. 317:729-730.

24. Webster, W.P., C.F. Zukoski, P. Hutchin, R.L. Reddick, S.R. Mandel, and G.P. Penick. 1971. Plasma factor VIII synthesis and control as revealed by canine organ transplantation. Am. J. Physiol. 220:1147-1154.

25. Groth, C.G., W.E. Hathaway, A. Gustafsson, W.P. Geis, C.W. Putnam, C. Bjorken, K.A. Porter, and T.E. Starzl. 1974. Correction of coagulation in the hemophilic dog by transplantation of lymphatic tissue. Surgery. 75:725-733.

26. Lewis, J.H., F.A. Bontempo, J.A. Spero, M.V. Ragni, and T.E. Starzl. 1985. Liver transplantation in a hemophiliac. N. Engl. J. Med. 312:1189-1190.

27. Bontempo, F.A., J.H. Lewis, T.J. Gorenc, J.A. Spero, M.V. Ragni, J.P. Scott, and T.E. Starzl. 1987. Liver transplantation in hemophilia A. Blood. 69: 1721-1724.

28. Liu, L., S. Xia, and J. Seifert. 1994. Transplantation of spleen cells in patients with hemophilia A. Transplant. Int. 7:201-206.

29. Pittman, D.D., M. Milleson, K. Marquette, K. Bauer, and R.J. Kaufman. 1992. A2 domain of human recombinant-derived Factor VIII is required for procoagulant activity but not for thrombin cleavage. Blood. 79:389-397.

30. Pittman, D.D., K.A. Marquette, and R.J. Kaufman. 1994. Role of the B domain for factor VIII and factor V expression and function. Blood. 84:42144225 .

31. Kaufman, R.J., L.C. Wasley, and A.J. Dorner. 1988. Synthesis, processing, and secretion of recombinant human Factor VIII expressed in mammalian cells. J. Biol. Chem. 263:6352-6362.

32. Kroner, P.A., P.A. Foster, S.A. Fahs, and R.R. Montgomery. 1996. The defective interaction between von Willebrand factor and Factor VIII in a patient with type 1 von Willebrand disease is caused by substitution of Arg19 and His54 in mature von Willebrand factor. Blood. 87:1013-1021.

33. Moore, H.-P.H., M.D. Walker, F. Lee, and R.B. Kelly. 1983. Expressing a human proinsulin cDNA in a mouse ACTH-secreting cell. Intracellular storage, proteolytic processing, and secretion on stimulation. Cell. 35:531-538.

34. Dorner, A.J., L.C. Wasley, and R.J. Kaufman. 1989. Increased synthesis of secreted proteins induces expression of glucose-regulated proteins in butyrate-treated Chinese hamster ovary cells. J. Biol. Chem. 264:20602-20607.
35. Wagner, D.D., S. Saffaripour, R. Bonfanti, J.E. Sadler, E.M. Cramer, B. Chapman, and T.N. Mayadas. 1991. Induction of specific storage organelles by von Willebrand factor propolypeptide. Cell. 64:403-413.

36. Scott, J.P., and R.R. Montgomery. 1991. The rapid differentiation of type IIb vWd from platelet-type (pseudo-) vWd by the "neutral" monoclonal antibody binding assay. Am. J. Clin. Pathol. 96:723-725.

37. Nishino, M., J.P. Girma, C. Rothschild, E. Fressinaud, and D. Meyer. 1989. New variant of von Willebrand disease with defective binding to factor VIII. Blood. 74:1591-1599.

38. Dorner, A.J., and R.J. Kaufman. 1990. Analysis of synthesis, processing, and secretion of proteins expressed in mammalian cells. Methods Enzymol. 185 $577-596$.

39. Vischer, U.M., and D.D. Wagner. 1994. von Willebrand factor proteolytic processing and multimerization precede the formation of WeibelPalade bodies. Blood. 83:3536-3544

40. Hattori, R., K.K. Hamilton, R.D. Fugates, R.P. McEver, and P.J. Sims. 1989. Stimulated secretion of endothelial von Willebrand factor is accompanied by rapid redistribution to the cell surface of the intracellular granule membrane protein GMP-140. J. Biol. Chem. 264:7768-7771.

41. Dorner, A.J., L.C. Wasley, and R.J. Kaufman. 1992. Overexpression of GRP78 mitigates stress induction of glucose regulated proteins and blocks secretion of selective proteins in Chinese hamster ovary cells. EMBO (Eur. Mol. Biol. Organ.) J. 4:1563-1571.

42. Fallaux, F.J., R.C. Hoeben, S.J. Cramer, D.J.M. van der Wollenberg, E. Briet, H. van Ormondt, and A.J. van der Eb. 1996. The human clotting factor FVIII cDNA contains an autonomously replicating sequence consensus- and matrix attachment region-like sequence that binds a nuclear factor, represses heterologous gene expression, and mediates the transcriptional effects of sodium butyrate. Mol. Cell Biol. 16:4264-4272.

43. Pittman, D.D., E.M. Alderman, K.N. Tomkinson, J.H. Wang, A.R. Giles, and R.J. Kaufman. 1993. Biochemical, immunological, and in vivo func tional characterization of B-domain-deleted Factor VIII. Blood. 81:2925-2935.

44. Journet, A.M., S. Saffaripour, E.M. Cramer, D. Tenza, and D.D. Wagner. 1993. von Willebrand factor storage requires intact prosequence cleavage site. Eur. J. Cell Biol. 60:31-41.

45. Hop, C., R. Fontijn, J.A. van Mourik, and H. Pannekoek. 1997. Polarity of constitutive and regulated von Willebrand factor secretion by transfected MDCK-II cells. Exp. Cell Res. 230:352-361.

46. Voorberg, J., R. Fontijn, J. Calafat, H. Janssen, J.A. van Mourik, and H Pannekoek. 1993. Biogenesis of von Willebrand factor-containing organelles in heterologous transfected CV-1 cells. EMBO (Eur. Mol. Biol. Organ.) J. 12: $749-758$.

47. Sedlak, B.J., F.M. Booyse, S. Bell, and M.E. Rafelson, Jr. 1976. Comparison of two types of endothelial cells in long term culture. Thromb. Haemostasis. 35:167-177.

48. Burgess, T.L., C.S. Craik, and R.B. Kelly. 1985. The exocrine protein trypsinogen is targeted into the secretory granules of an endocrine cell line: studies by gene transfer. J. Cell Biol. 101:639-645.

49. Kaufman, R.J., L.C. Wasley, M.V. Davies, R.J. Wise, D.I. Israel, and A.J. Dorner. 1989. Effect of von Willebrand factor coexpression on the synthesis and secretion of factor VIII in Chinese hamster ovary cells. Mol. Cell. Biol. 9:1233-1242.

50. Menache, D., D.L. Aronson, F. Darr, R.R. Montgomery, J.C. Gill, C.M Kessler, J.M. Lusher, P.D. Phatak, A.D. Shapiro, A.R. Thompson, and G.C. White II. 1996. Pharmacokinetics of von Willebrand factor and factor VIIIC in patients with severe von Willebrand disease (type 3 VWD): estimation of the rate of factor VIIIC synthesis. Br. J. Haematol. 94:740-745.

51. Mazurier, C., and D. Meyer. 1996. Factor VIII binding assay of von Willebrand factor and diagnosis of type $2 \mathrm{~N}$ von Willebrand disease: results of an international survey. Thromb. Haemostasis. 76:270-274.

52. Kroner, P.A., P.A. Foster, S.A. Fahs, and R.R. Montgomery. 1993. Persistence of pro-vWF, an inherited cause of reduced factor VIII binding, and its comparison with other factor VIII binding vWF mutants. Thromb. Haemostasis. 69:1212a. (Abstr.)

53. Vischer, U.M., and D.D. Wagner. 1994. von Willebrand factor proteolytic processing and multimerization precede the formation of WeibelPalade bodies. Blood. 83:3536-3544.

54. Wagner, D.D., P.J. Fay, L.A. Sporn, S. Sinha, S.O. Lawrence, and V.J. Marder. 1987. Divergent fates of von Willebrand factor and its propolypeptide (von Willebrand antigen II) after secretion from endothelial cells. Proc. Natl. Acad. Sci. USA. 84:1955-1959.

55. Wise, R.J., A.J. Dorner, M. Krane, D.D. Pittman, and R.J. Kaufman. 1991. The role of von Willebrand factor multimers and propeptide cleavage in the binding and stabilization of factor VIII. J. Biol. Chem. 266:21948-21955.

56. Michnick, D.A., D.D. Pittman, R.J. Wise, and R.J. Kaufman. 1994. Identification of individual tyrosine sulfation sites within Factor VIII required for optimal activity and efficient thrombin cleavage. J. Biol. Chem. 269:2009520102.

57. Wagner, D.D. 1993. The Weibel-Palade body: the storage granule for von Willebrand factor and P-selectin. Thromb. Haemostasis. 70:105-110. 